\title{
RELAP-7 Pressurizer Component Development Updates
}

Haihua Zhao

Hongbin Zhang

Ling Zou

Richard Martineau

Michael Holten

Qiao Wu

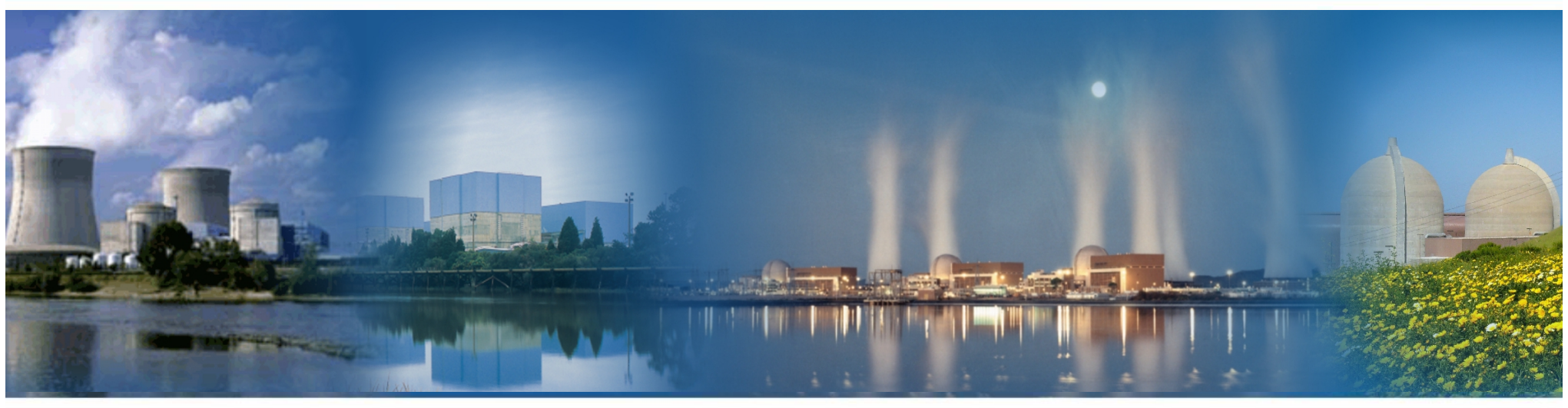




\section{DISCLAIMER}

This information was prepared as an account of work sponsored by an agency of the U.S. Government. Neither the U.S. Government nor any agency thereof, nor any of their employees, makes any warranty, expressed or implied, or assumes any legal liability or responsibility for the accuracy, completeness, or usefulness, of any information, apparatus, product, or process disclosed, or represents that its use would not infringe privately owned rights. References herein to any specific commercial product, process, or service by trade name, trade mark, manufacturer, or otherwise, does not necessarily constitute or imply its endorsement, recommendation, or favoring by the U.S. Government or any agency thereof. The views and opinions of authors expressed herein do not necessarily state or reflect those of the U.S. Government or any agency thereof. 
RELAP-7 Pressurizer Component Development Updates

Haihua Zhao ${ }^{1}$, Hongbin Zhang ${ }^{1}$, Ling Zou ${ }^{1}$, Richard Martineau ${ }^{1}$, Michael Holten ${ }^{2}$, Qiao $\mathbf{W u}^{2}$

March 2016

${ }^{1}$ Idaho National Laboratory Idaho Falls, Idaho 83415

${ }^{2}$ Department of Nuclear Engineering and Radiation Health Physics Oregon State University Corvallis, OR 97331

Prepared for the U.S. Department of Energy Office of Nuclear Energy Under DOE Idaho Operations Office

Contract DE-AC07-05ID14517 


\section{EXECUTIVE SUMMARY}

RELAP-7 is a nuclear systems safety analysis code being developed at the Idaho National Laboratory (INL). RELAP-7 development began in 2011 to support the Risk Informed Safety Margins Characterization (RISMC) Pathway of the Light Water Reactor Sustainability (LWRS) program. The overall design goal of RELAP-7 is to take advantage of the previous thirty years of advancements in computer architecture, software design, numerical methods, and physical models in order to provide capabilities needed for the RISMC methodology and to support nuclear power safety analysis. The code is being developed based on Idaho National Laboratory's modern scientific software development framework - MOOSE (the Multi-Physics Object-Oriented Simulation Environment). The initial development goal of the RELAP-7 approach focused primarily on the development of an implicit algorithm capable of strong (nonlinear) coupling of the dependent hydrodynamic variables contained in the 1-D/2-D flow models with the various 0-D system reactor components that compose various boiling water reactor (BWR) and pressurized water reactor nuclear power plants (NPPs).

As part of the efforts to expand the capability for PWR simulation, an equilibrium single-region pressurizer model has been implemented in RELAP-7. The pressurizer component can simulate pressure and water level change through insurge, spray, and heating processes. Two simple tests - one for insurge process and another for outsurge process have been reported to demonstrate and verify the functions of the pressurizer model. The typical single-phase PWR system model presented in the first RELAP-7 milestone report has been updated, as part of system level test for the new pressurizer model. The updated PWR system model with the pressurizer component can be used for more realistic transient simulations.

The addition of the equilibrium single-region pressurizer model represents the first step of developing a suite of pressurizer models with different levels of fidelities. Nonequilibrium two-region two-zone model and non-equilibrium five-region three zone model will be implemented in the near future. Cross comparison and validation will be pursued when higher fidelity pressurizer models are completed. 


\section{ACKNOWLEDGEMENTS}

We would like to acknowledge Stephen Hess and Greg Swindlehurst of the Electric Power Research Institute for their valuable contributions to development of the RELAP-7 applications. Their expertise in nuclear engineering, systems analysis and understanding of industry needs is much appreciated. We also acknowledge contributions of the MOOSE team. 


\section{CONTENTS}

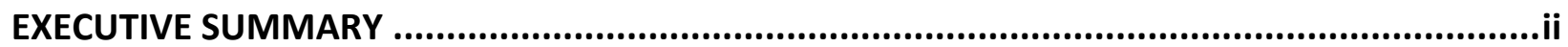

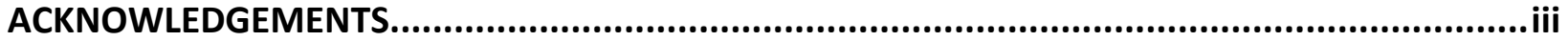

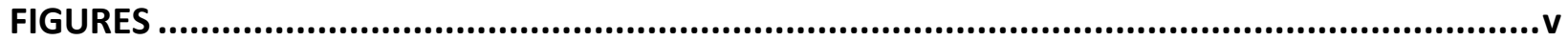

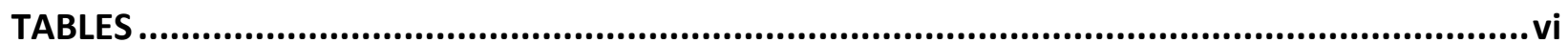

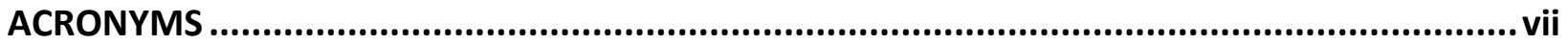

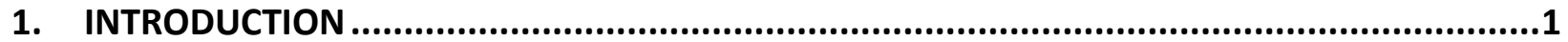

2. RELAP-7 Pressurizer Component Development Status Update ........................................3

2.1 Equilibrium Single-Region Pressurizer Model................................................................ 3

2.2 Update on Single-Phase PWR Model with the Pressurizer Model..........................................10

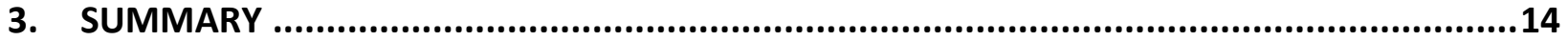

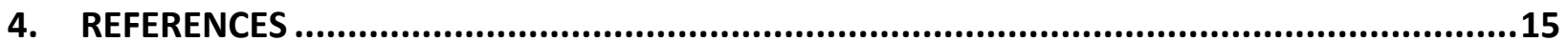




\section{FIGURES}

Figure 1. Pressurizer and Pressurizer Relief Tank (credit of U.S. NRC [6]) ............................................2

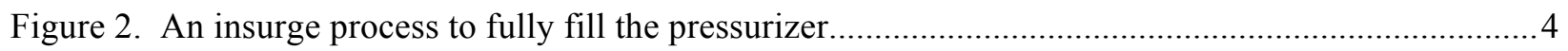

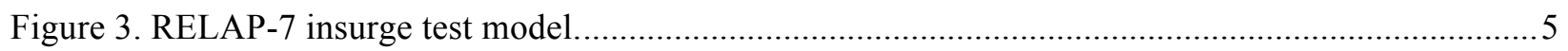

Figure 4. Calculated water level for the insurge test. .....................................................................

Figure 5. Calculated total fluid mass and total liquid mass in the pressurizer for the insurge test............... 6

Figure 6. Calculated pressure in the pressurizer for the insurge test. .................................................. 6

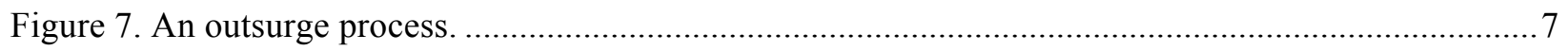

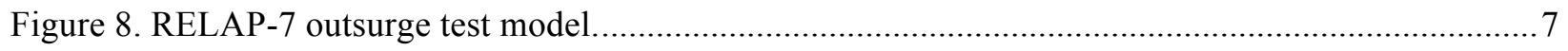

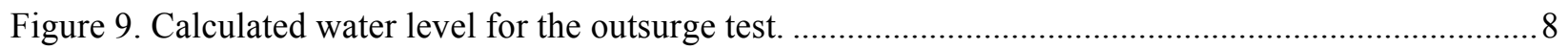

Figure 10. Calculated total fluid mass and total liquid mass in the pressurizer for the outsurge test............ 8

Figure 11. Calculated pressure in the pressurizer for the outsurge test. .................................................. 9

Figure 12. Schematics of the updated single phase PWR model...................................................... 11

Figure 13. Calculated pressure in the pressurizer for the PWR test. ....................................................11

Figure 14. Calculated water level in the pressurizer for the PWR test.................................................. 12

Figure 15. Calculated total fluid mass and total water mass in the pressurizer for the PWR test..............12

Figure 16. Calculated surge line flow rate in the pressurizer for the PWR test.......................................13

Figure 17. Calculated total specific energy in the lower plenum in the pressurizer for the PWR test........13 
TABLES

Table 1. Typical pressurizer design parameters 


\section{ACRONYMS}

$\begin{array}{ll}\text { 0-D } & \text { zero-dimensional } \\ \text { 1-D } & \text { one-dimensional } \\ \text { 2-D } & \text { two-dimensional } \\ \text { BWR } & \text { boiling water reactor } \\ \text { FY } & \text { fiscal year } \\ \text { INL } & \text { Idaho National Laboratory } \\ \text { LWRS } & \text { Light Water Reactor Sustainability } \\ \text { MOOSE } & \text { Multi-Physics Object-Oriented Simulation Environment } \\ \text { RELAP-7 } & \text { Reactor Excursion and Leak Analysis Program } 7 \\ \text { RISMC } & \text { risk informed safety margin characterization } \\ \text { PWR } & \text { pressurized water reactor } \\ \text { SBO } & \text { station blackout }\end{array}$




\section{INTRODUCTION}

RELAP-7 is a nuclear systems safety analysis code being developed at the Idaho National Laboratory (INL) [1-5] and is the new generation tool in the RELAP reactor safety/systems analysis application series. RELAP-7 development began in 2011 to support the Risk Informed Safety Margins Characterization (RISMC) Pathway of the Light Water Reactor Sustainability (LWRS) program. The overall design goal of RELAP-7 is to take advantage of the previous thirty years of advancements in computer architecture, software design, numerical methods, and physical models in order to provide capabilities needed for the RISMC methodology and to support nuclear power safety analysis. The code is being developed based on Idaho National Laboratory's modern scientific software development framework - MOOSE (the Multi-Physics Object-Oriented Simulation Environment).

Since Fiscal Year (FY) 2015, the major development effort of the RELAP-7 code has been shifted from establishing boiling water reactor (BWR) station blackout (SBO) demonstration analysis capability to add more capability to simulate pressurized water reactor (PWR) analysis. One of the efforts is to develop pressurizer models. The development work for pressurizer models has been carried out with the collaboration between INL RELAP-7 team and Oregon State University. As an additional benefit, next generation of advanced code developers can be trained as part of the efforts.

The pressurizer is the component in the reactor coolant system which provides a means of controlling the system pressure. Pressure is controlled by the use of electrical heaters, pressurizer spray, power operated relief valves, and safety valves. Figure 1 shows a typical pressurizer system [6]. If the pressure increases and exceeds the desired setpoint, the spray line will spray cold water into the steam space. The cold water will condense the steam into water, which will reduce pressure. If pressure continues to increase, the pressurizer relief valves will open and dump steam to the pressurizer relief tank. If this does not relieve pressure, the safety valves will lift, also discharging to the pressurizer relief tank. If pressure starts to decrease, the electrical heaters will be turned on to boil more water into steam, and therefore increase pressure.

The pressurizer model development work has been planned in a sequence of several models with increasing complexity, fidelity, and capability to capture more detailed physics: (1) equilibrium singleregion model [7], (2) non-equilibrium two-region two-zone model [7], and (3) non-equilibrium fiveregion three zone model [8]. When we implement different pressurizer models with different fidelity, we can compare each model against each other and experimental data. The model uncertainties can be quantified step by step when we know which approximations are removed. Further improvement can be identified. This report covers the first pressurizer model implemented - equilibrium single-region model. The major features and two simple tests - one for insurge case and another for outsurge case will be presented. With the new addition of the pressurizer model, the typical single-phase PWR system model presented in the first RELAP-7 milestone report has been updated, as part of system level tests for the new pressurizer model. 


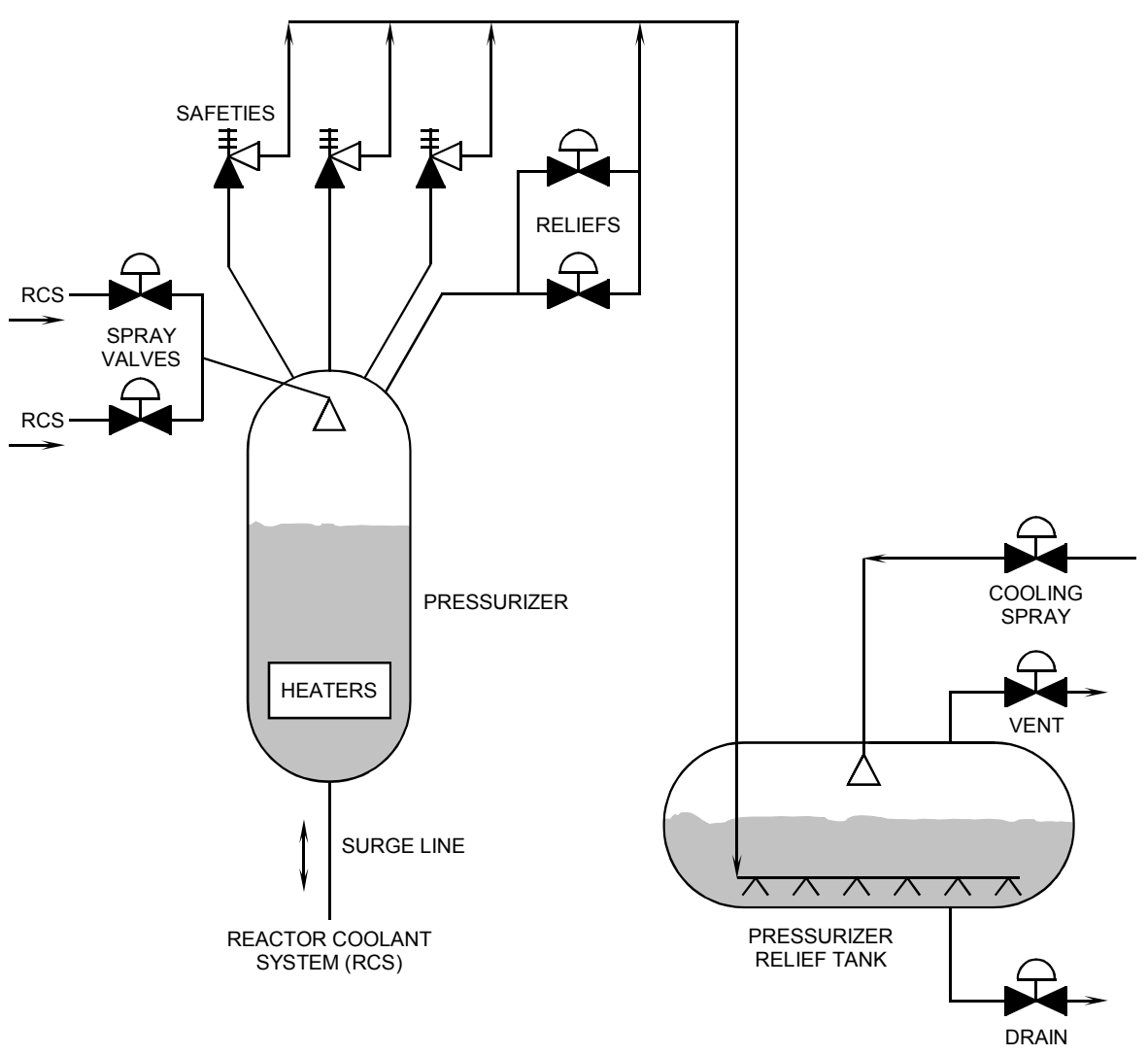

Figure 1. Pressurizer and Pressurizer Relief Tank (credit of U.S. NRC [6]) 


\section{RELAP-7 Pressurizer Component Development Status Update}

This section provides a status update on the pressurizer component development, tests, and future works.

\subsection{Equilibrium Single-Region Pressurizer Model}

A new pressurizer component has been successfully developed in RELAP-7. It is based on the equilibrium single-region model [7]. In this model, the following assumptions are used:

- Using a lumped parameter model (0-D) since spatial gradients are small.

- Equilibrium states for both vapor and liquid regions,

- Consider insurge/outsurge, spray, and heating,

- Ignoring wall thermal capacity.

In making these assumptions, any real phase change processes (rainout, evaporation, etc.) occur instantaneously, so this model would be ill-suited to predict the behavior of rapid transients. However, in any process where the characteristic time scale of the transient is much longer than that of the phase change processes, this model should suffice.

Only three equations for mass, energy, and total volume conservations are required to describe the model. Additional boundary conditions for surge line connection and spray line connection are needed. Water level and total water mass are two important auxiliary variables for outputs. To simulate a complete pressurizer function, additional components are needed to connect to the pressurizer component, such as surge line pipe, spray line pipe, spray line mass flow rate control and proper boundary components if not connected to other components. The spray line mass flow rate control function can be realized in RELAP-7 by using time dependent mass flow rate (TDM) component or ideal pump component. The heater power rate parameter in the pressurizer component and the spray line mass flow rate are control variables to realize the pressure control.

Two simple test cases are shown in this report to verify the functions of the pressurizer component. Table 1 shows the typical pressurizer design parameters used for the tests [7]. The first test simulates the insurge process as shown in Figure 2. The maximal insurge amount is uniformly injected into the pressurizer over 100 seconds $(95 \mathrm{~kg} / \mathrm{s})$. In order to control the pressure increase, heaters need to be turned on with a heating rate of $1.06 \times 10^{5} \mathrm{~W}$ and the spray of cold water is enabled with a mass flow rate of $3 \%$ of the insurge rate $(2.85 \mathrm{~kg} / \mathrm{s})$. At the end of the process, the pressurizer is totally filled with water. The schematic of the RELAP-7 simulation model is shown in Figure 3. The mass flow rates through the surge line and the spray line are controlled through two TDM components. Figures 4-6 show the RELAP-7 simulation results for water level, total fluid mass and liquid mass, and pressure. In Figure 4, the water level reaches the top at the end of insurge process, which is also shown in Figure 5 in which all the fluid in the pressurizer is water at the end of the insurge process. In the simulation, two periods before and after the transient are intentionally used to reach steady states. The pressurizer pressure is maintained very well during the insurge process as shown in Figure 6. 
Table 1. Typical pressurizer design parameters

\begin{tabular}{|l|l|}
\hline Parameter & Value \\
\hline Total Volume $\left[\mathrm{m}^{3}\right]$ & 51.3 \\
\hline Cross Section Area $\left[\mathrm{m}^{2}\right]$ & 3.2063 \\
\hline Pressure $[\mathrm{MPa}]$ & 15.5 \\
\hline Saturation Temperature [K] & 618.3 \\
\hline Initial Water Mass $[\mathrm{kg}]$ & 18597 \\
\hline Mass of Maximal Outsurge $[\mathrm{kg}]$ & 14000 \\
\hline Mass of Maximal Insurge [kg] & 9500 \\
\hline Mass of Liquid Water to Cover the Heaters $[\mathrm{kg}]$ & 1827 \\
\hline Surge Line Water Source Temperature $[\mathrm{K}]$ & 597.2 \\
\hline Spray Line Water Source Temperature [K] & 560.9 \\
\hline
\end{tabular}

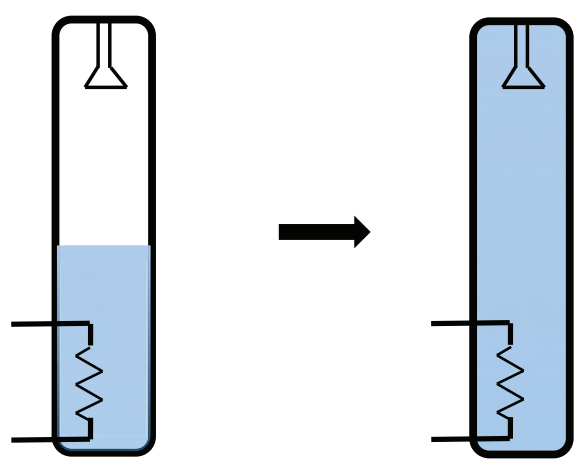

Figure 2. An insurge process to fully fill the pressurizer. 


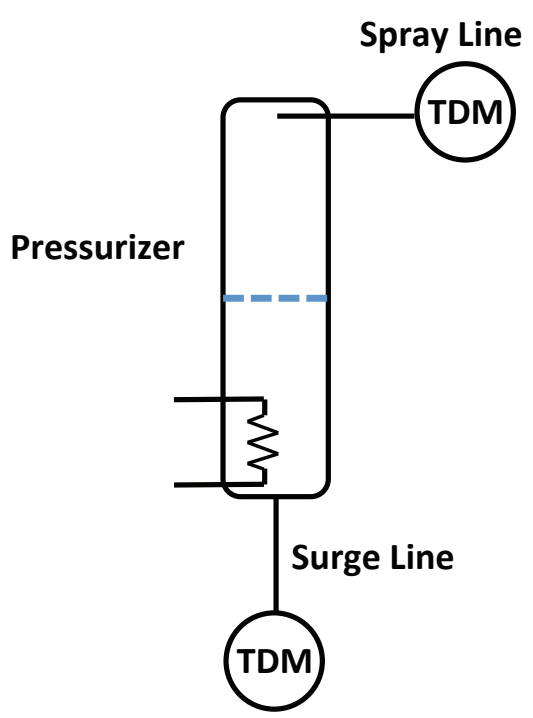

Figure 3. RELAP-7 insurge test model.

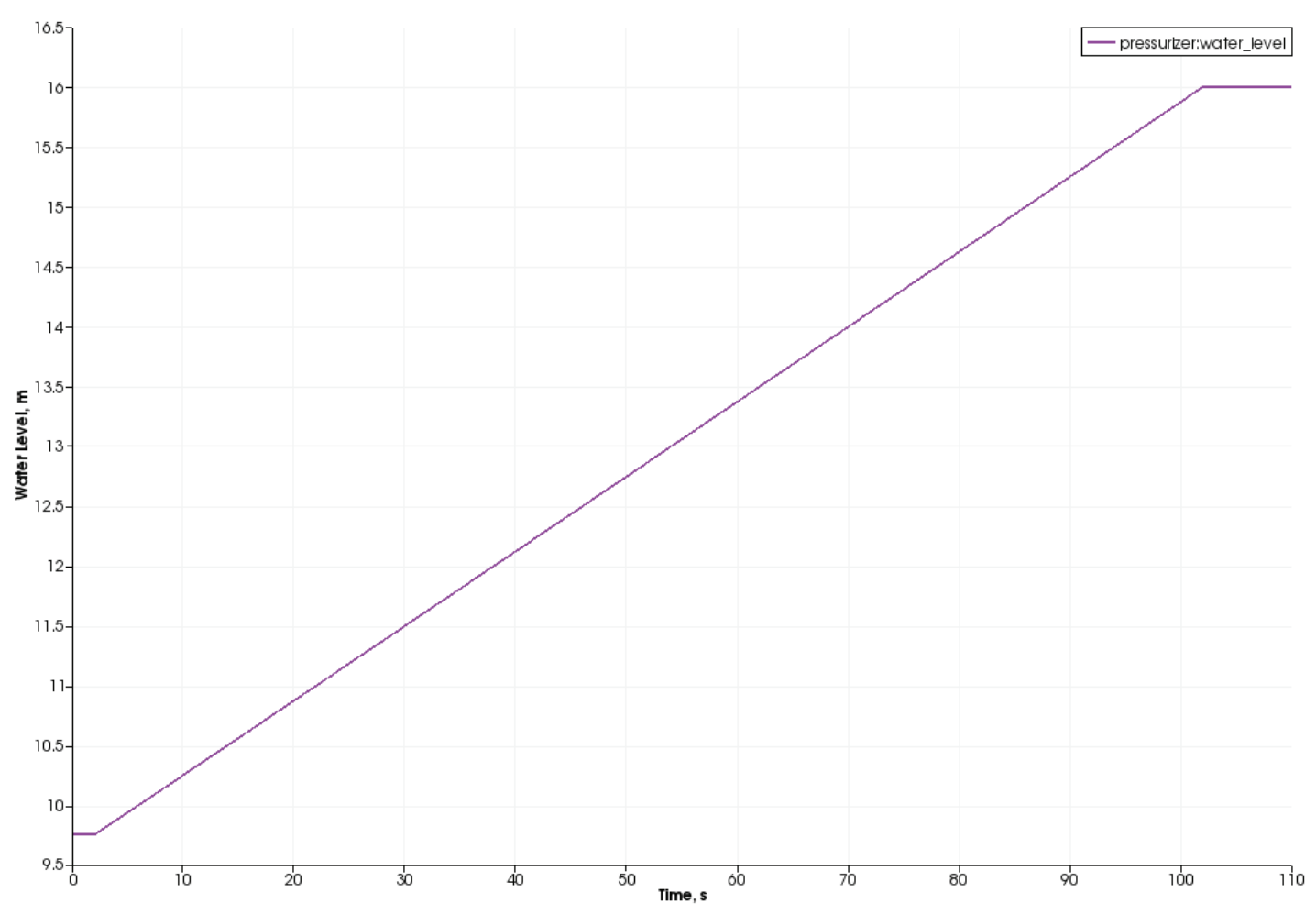

Figure 4. Calculated water level for the insurge test. 


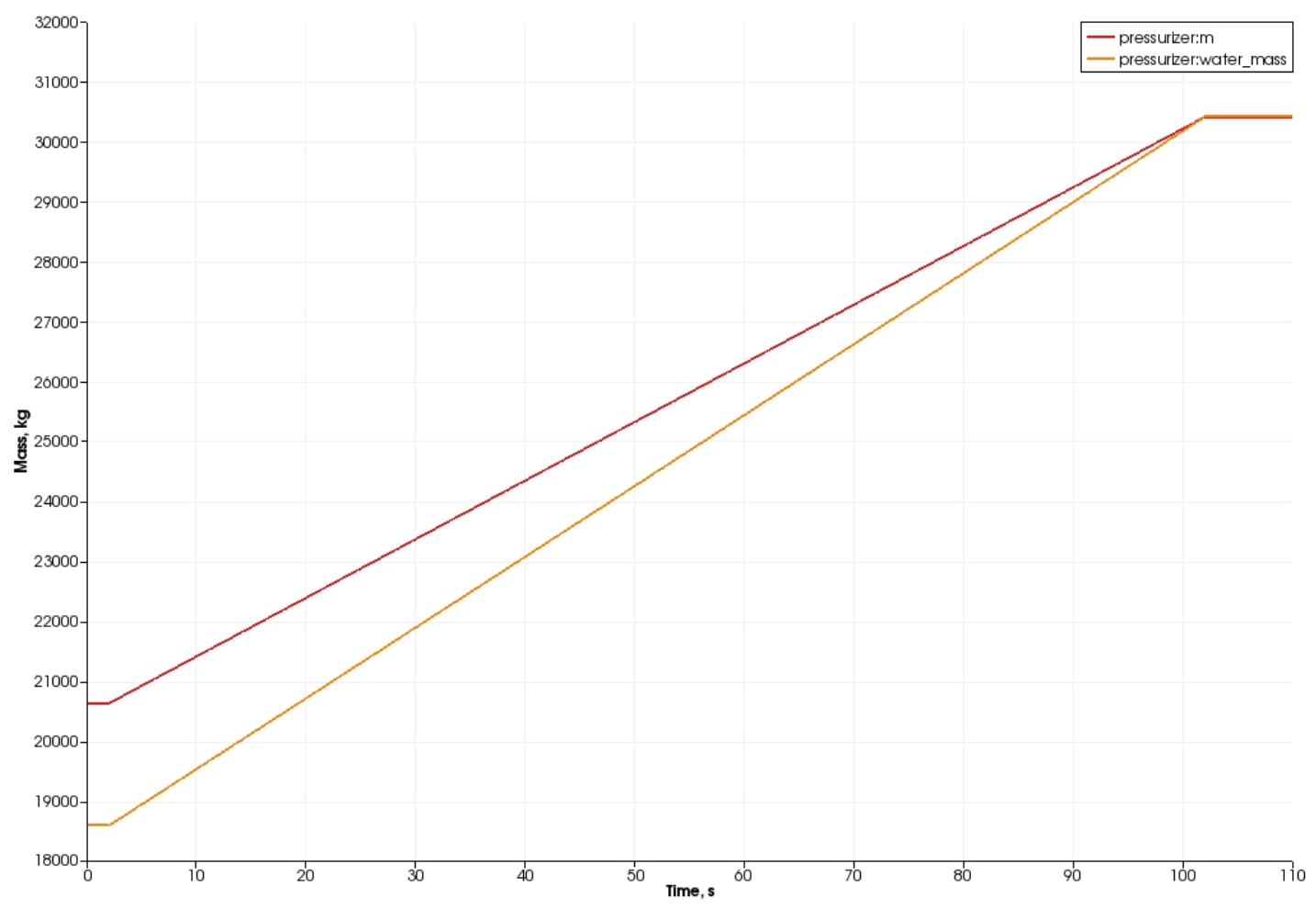

Figure 5. Calculated total fluid mass and total liquid mass in the pressurizer for the insurge test.

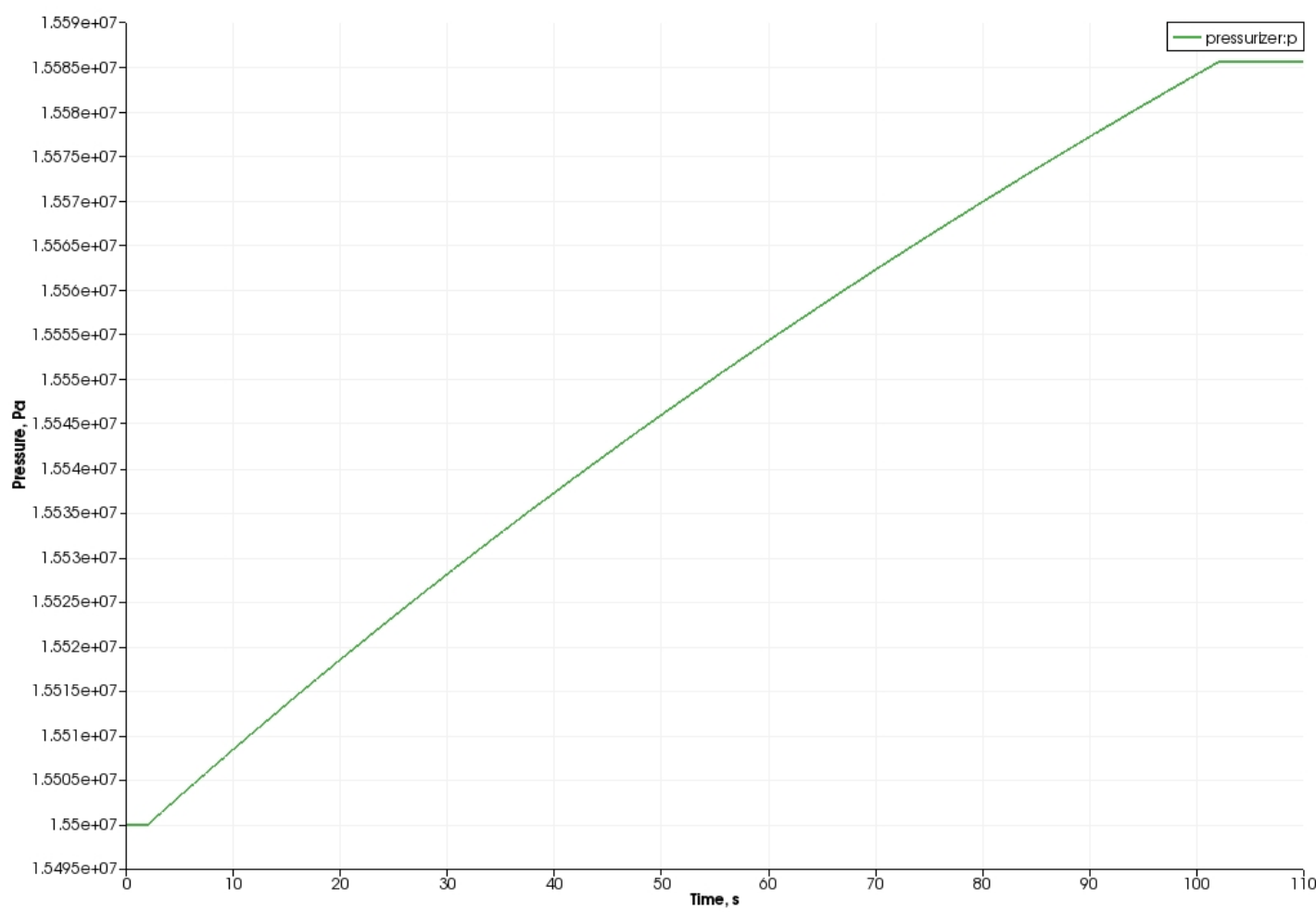

Figure 6. Calculated pressure in the pressurizer for the insurge test. 
The second test simulates the outsurge process as shown in Figure 7. The maximal outsurge amount is uniformly removed from the pressurizer over 2000 seconds $(7 \mathrm{~kg} / \mathrm{s})$. In order to control the pressure decrease, heaters need to be turned on with a heating rate of $1.4255 \times 10^{6} \mathrm{~W}$ and the spray of cold water is not used. At the end of the process, the pressurizer heaters are barely covered with water. The schematic of the RELAP-7 simulation model is shown in Figure 8. The mass flow rate through the surge line is controlled through one Ideal Pump component. Figures 9-11 show the RELAP-7 simulation results for water level, total fluid mass and liquid mass, and pressure. In the simulation, two short periods before and after the transient are intentionally used to maintain steady states. The pressurizer pressure is maintained very well during the outsurge process as shown in Figure 11.

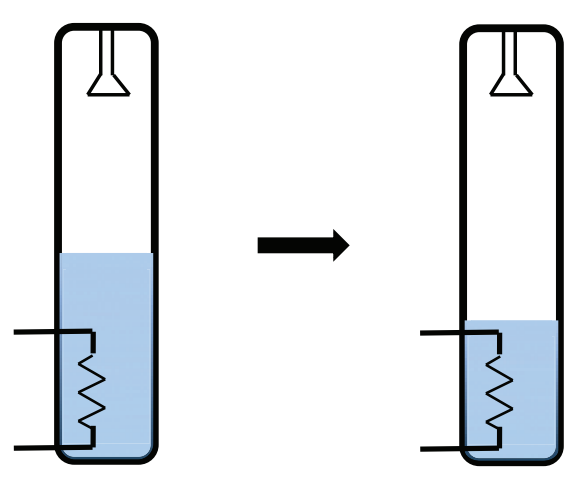

Figure 7. An outsurge process.

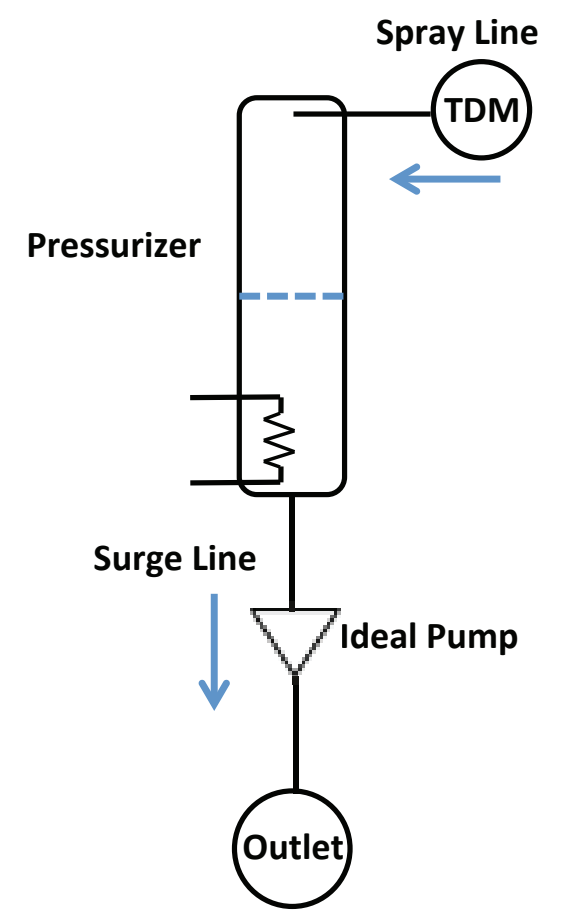

Figure 8. RELAP-7 outsurge test model. 


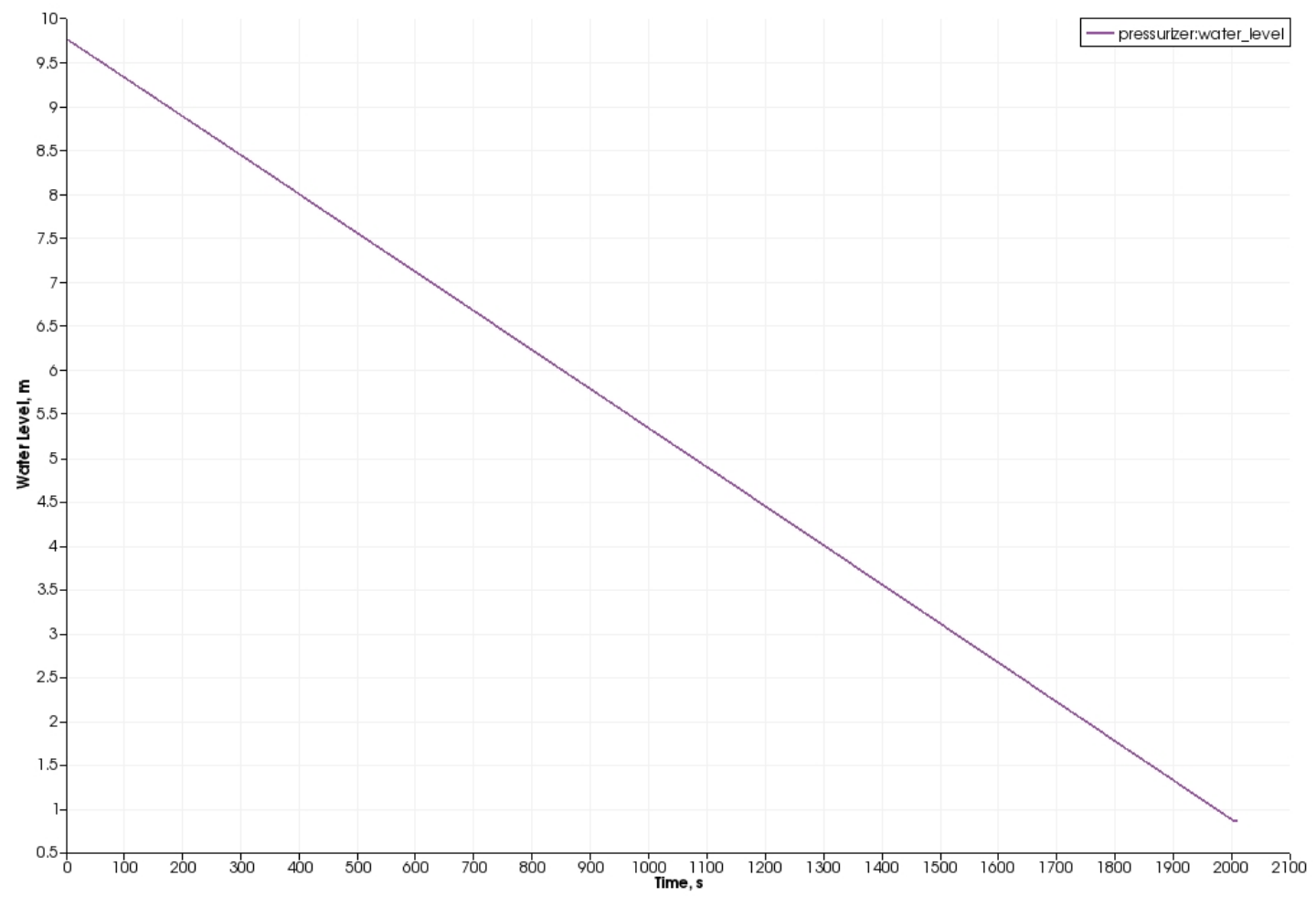

Figure 9. Calculated water level for the outsurge test.

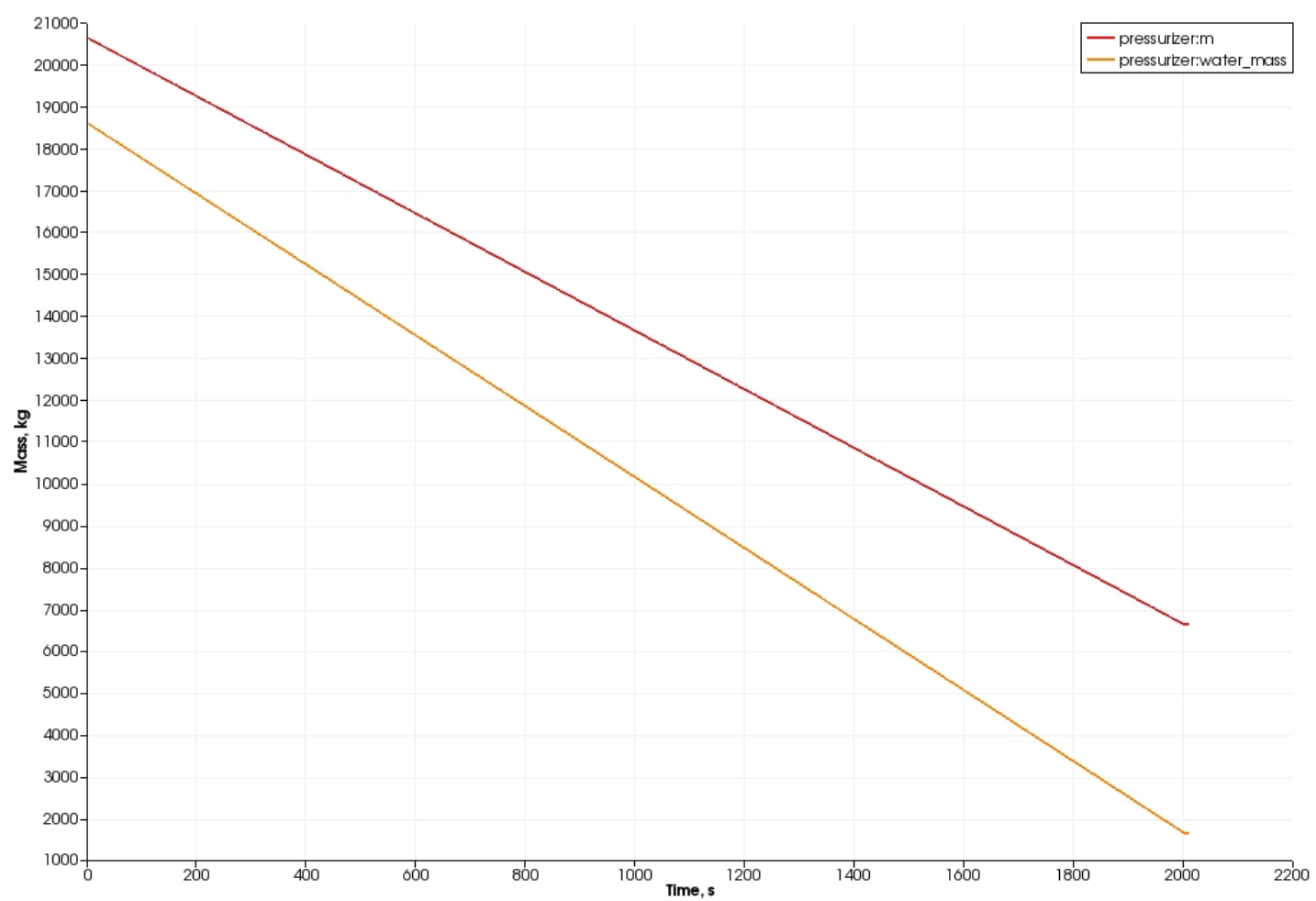

Figure 10. Calculated total fluid mass and total liquid mass in the pressurizer for the outsurge test. 


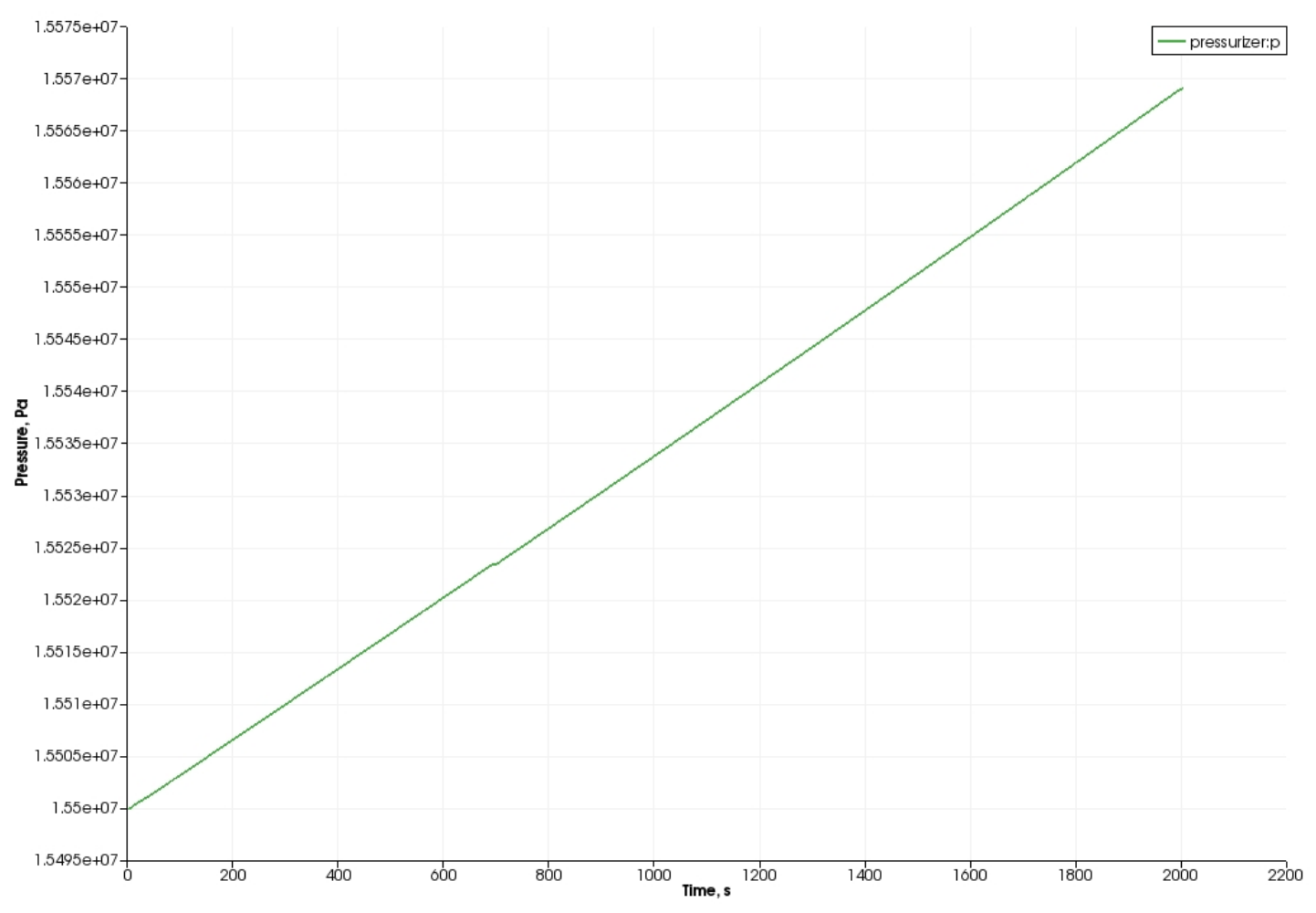

Figure 11. Calculated pressure in the pressurizer for the outsurge test. 


\subsection{Update on Single-Phase PWR Model with the Pressurizer Model}

With the new addition of the pressurizer model, the simplified single phase PWR system model presented in the first RELAP-7 milestone report [1] has been updated, as part of integral test for the new pressurizer model. In the original input model, the pressurizer function was simulated with a fixed boundary condition: pressure and temperature. In the updated input model as shown in Figure 12, the pressurizer spray line is connected to the loop A cold leg and the pressurizer surge line is connected to the loop A hot leg. An Ideal Pump component is used to control the spray mass flow rate. Same design parameters as shown in Table 1 is used for the single phase PWR system except for the system pressure: $15.17 \mathrm{e} 6 \mathrm{~Pa}$ is used here.

A simple control system is applied to the pressurizer component to control the system pressure:

- If pressure $\geq 15.171 \mathrm{e} 6 \mathrm{~Pa}$ :

$\circ$ heating rate $=0$

- spray rate $=10 . \mathrm{kg} / \mathrm{s}$

- If pressure $\leq 15.169 \mathrm{e} 6 \mathrm{~Pa}$ :

$\circ$ heating rate $=1.8 \mathrm{e} 6 \mathrm{~W}$

○ spray rate $=0$

- If $15.169 \mathrm{e} 6 \mathrm{~Pa}<$ pressure $<15.171 \mathrm{e} 6 \mathrm{~Pa}$ :

$\circ$ heating rate $=0$

- spray rate $=0$

The model was run for $90 \mathrm{~s}$ to reach the steady state. Figures 13 to 17 show the simulation results. With the heating of primary system, the average water density in the primary system becomes lower with time, which results in a larger water volume. The excessed water surges into the pressurizer as shown in Figure 16 and causes the pressurizer water level to rise up as shown in Figure 14. Due to lower temperature of the insurged water, the pressurizer pressure begins to drop in the beginning as shown in Figure 13. When the low pressure setting point is reached, the heaters are turned on to produce more steam, which begins to overcome the tendency of dropping pressure. At around $36 \mathrm{~s}$, the pressure in the pressurizer is restored to the design value. Small amount of water keeps to surge into the pressurizer as shown in Figures 15 and 16, until the steady state is reached. Figure 17 shows the specific total energy variation at the reactor lower plenum. We can clearly see several oscillations with quickly decayed magnitude with time. Other transient behaviors are the same as previously reported results [1] and are not repeated in this report. 


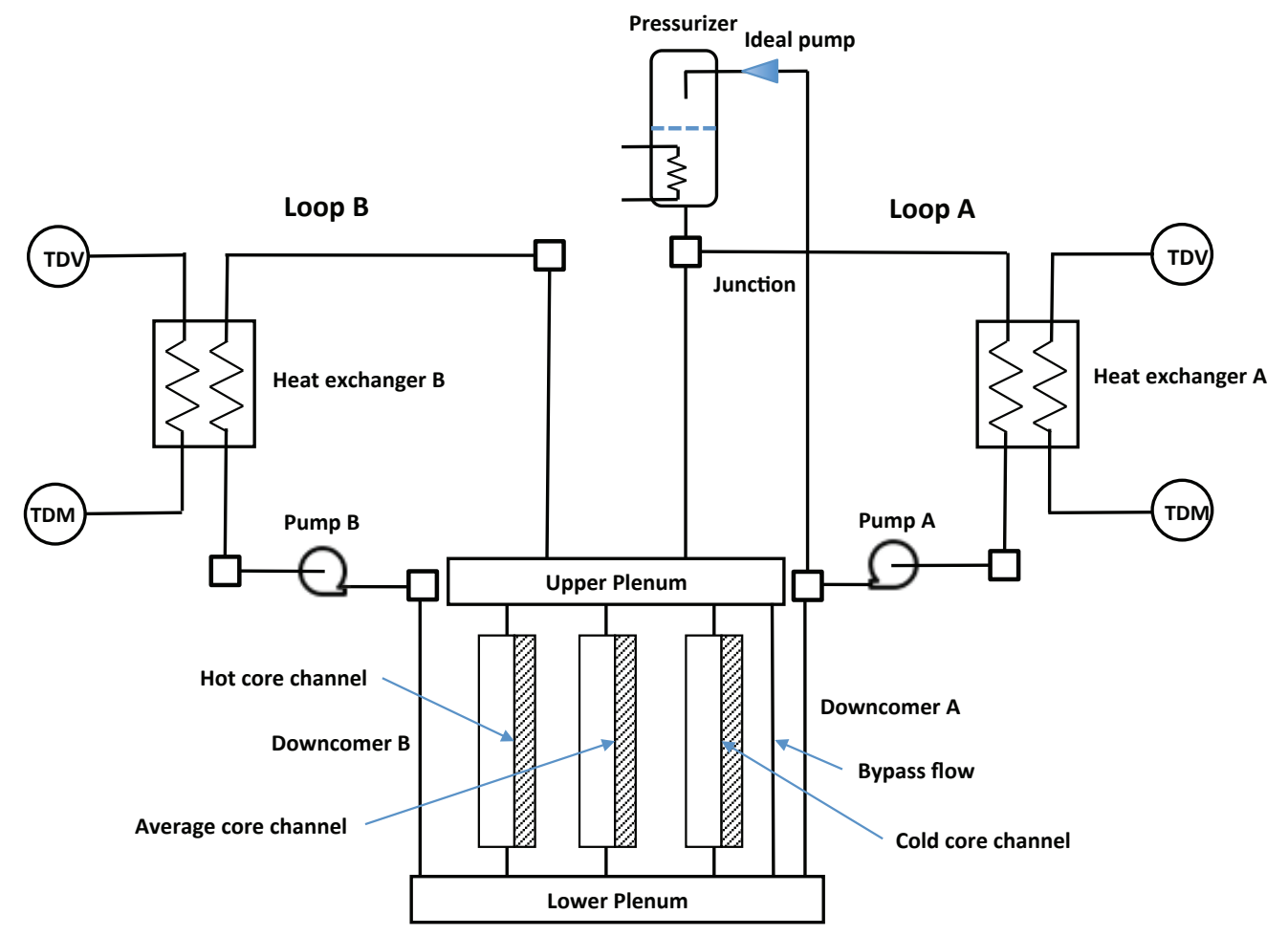

Figure 12. Schematics of the updated single phase PWR model.

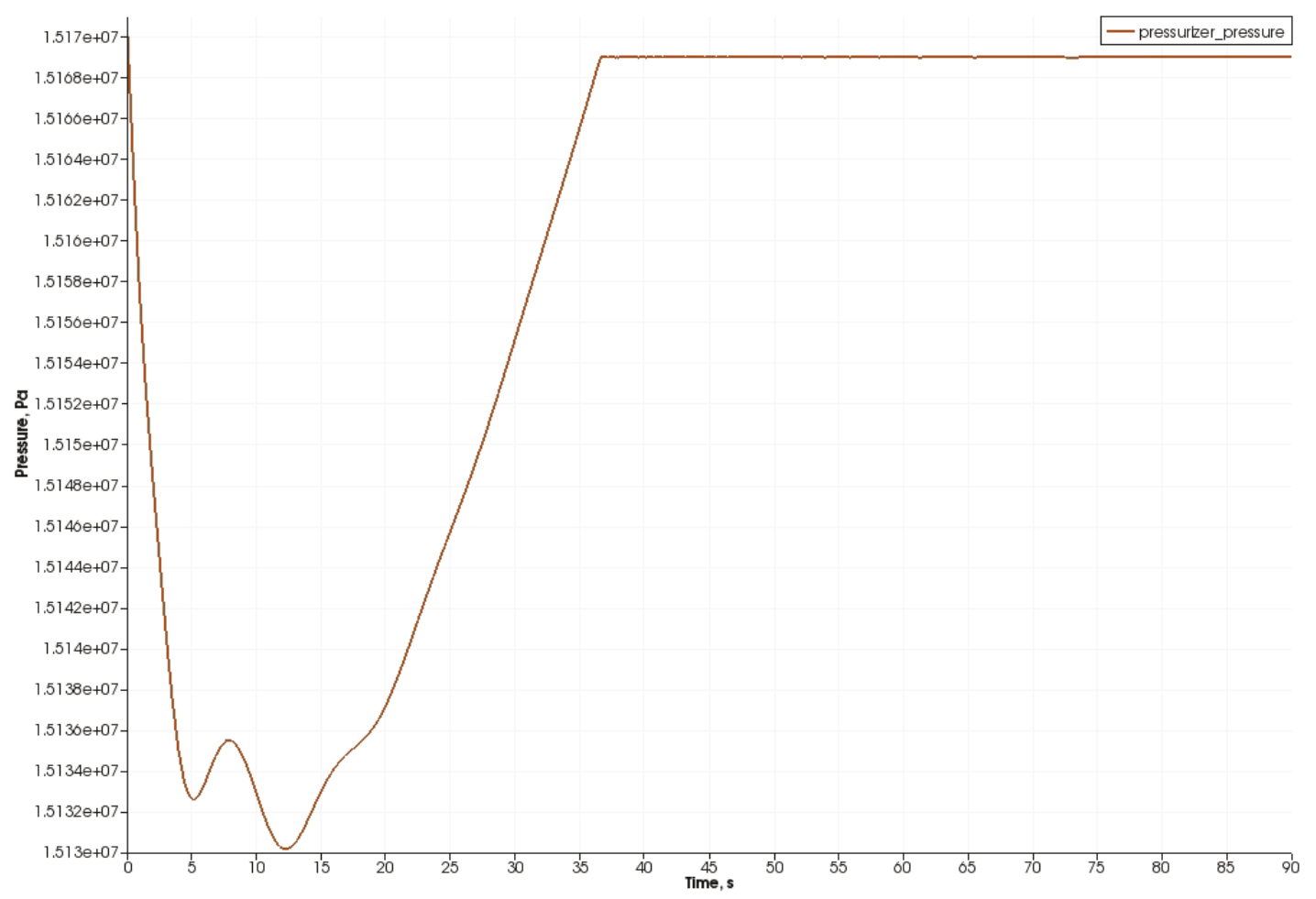

Figure 13. Calculated pressure in the pressurizer for the PWR test. 


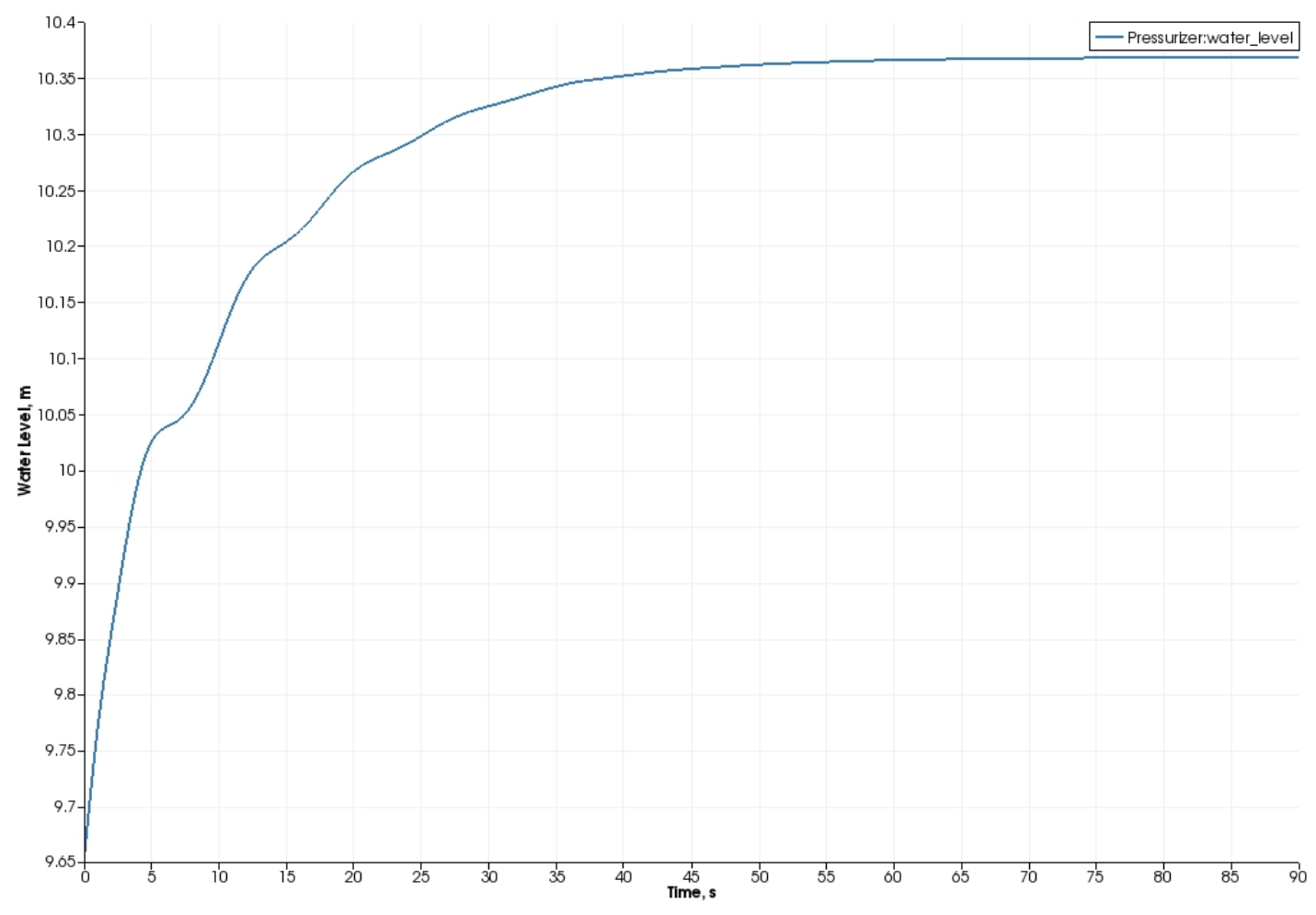

Figure 14. Calculated water level in the pressurizer for the PWR test.

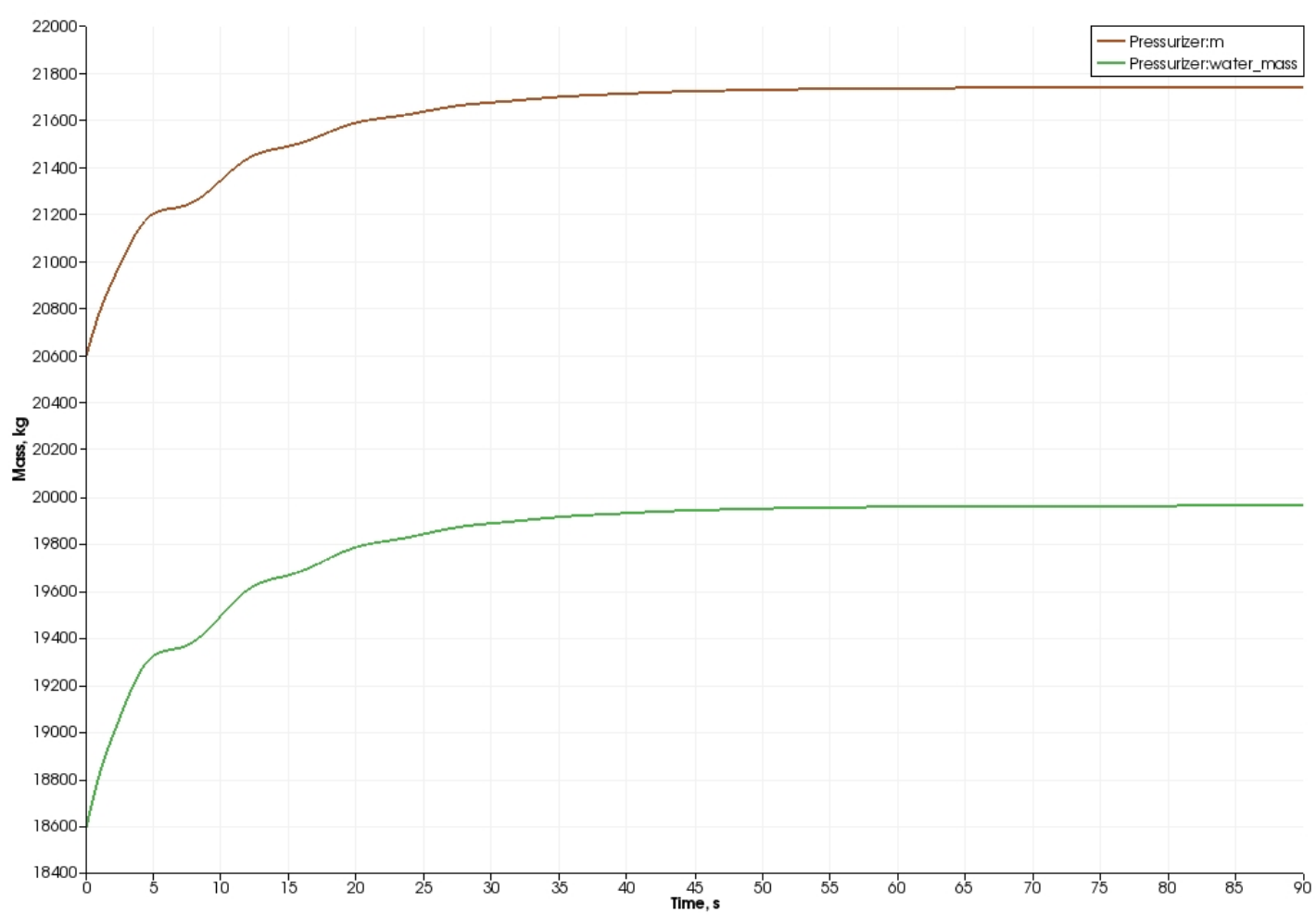

Figure 15. Calculated total fluid mass and total water mass in the pressurizer for the PWR test. 


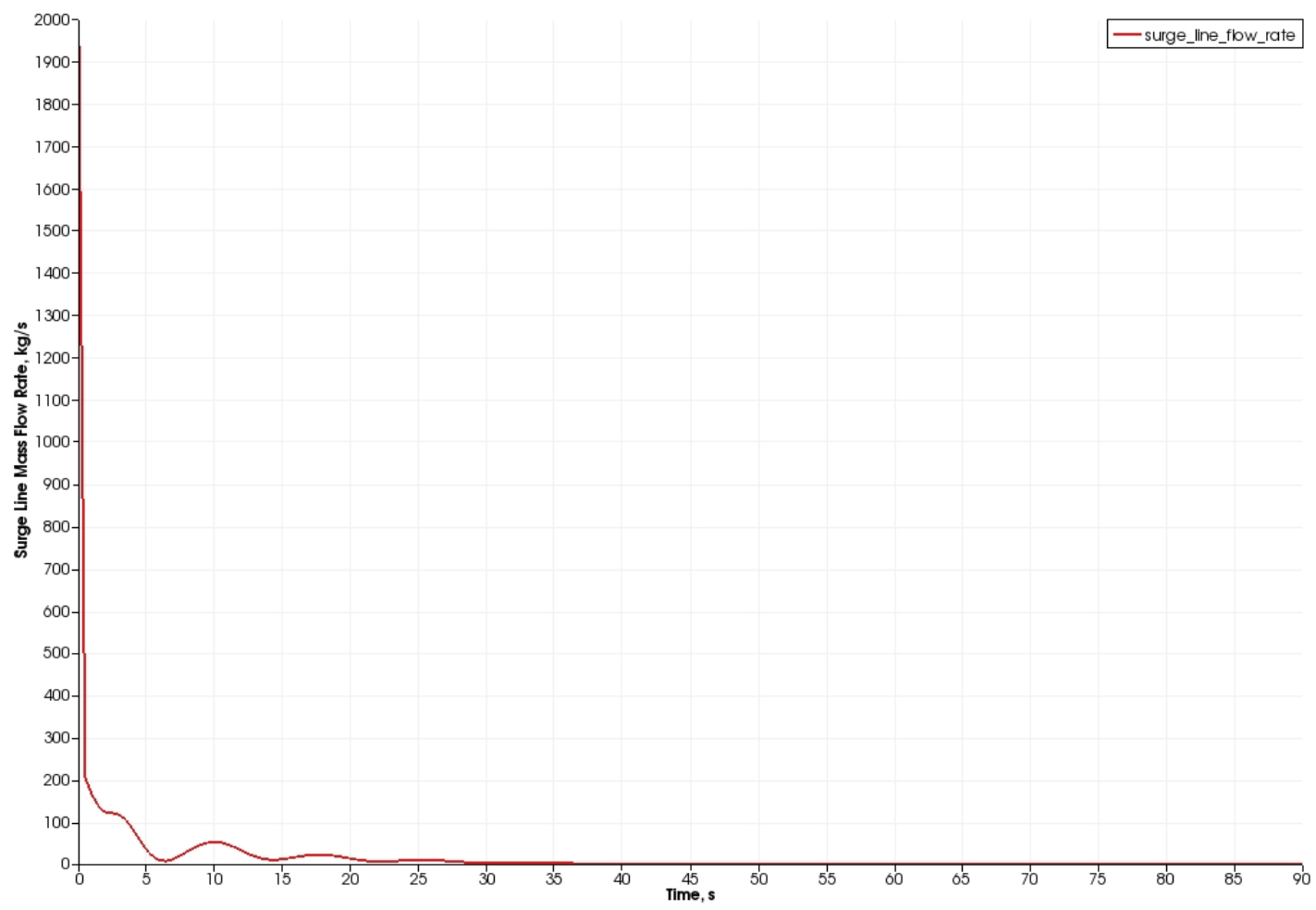

Figure 16. Calculated surge line flow rate in the pressurizer for the PWR test.

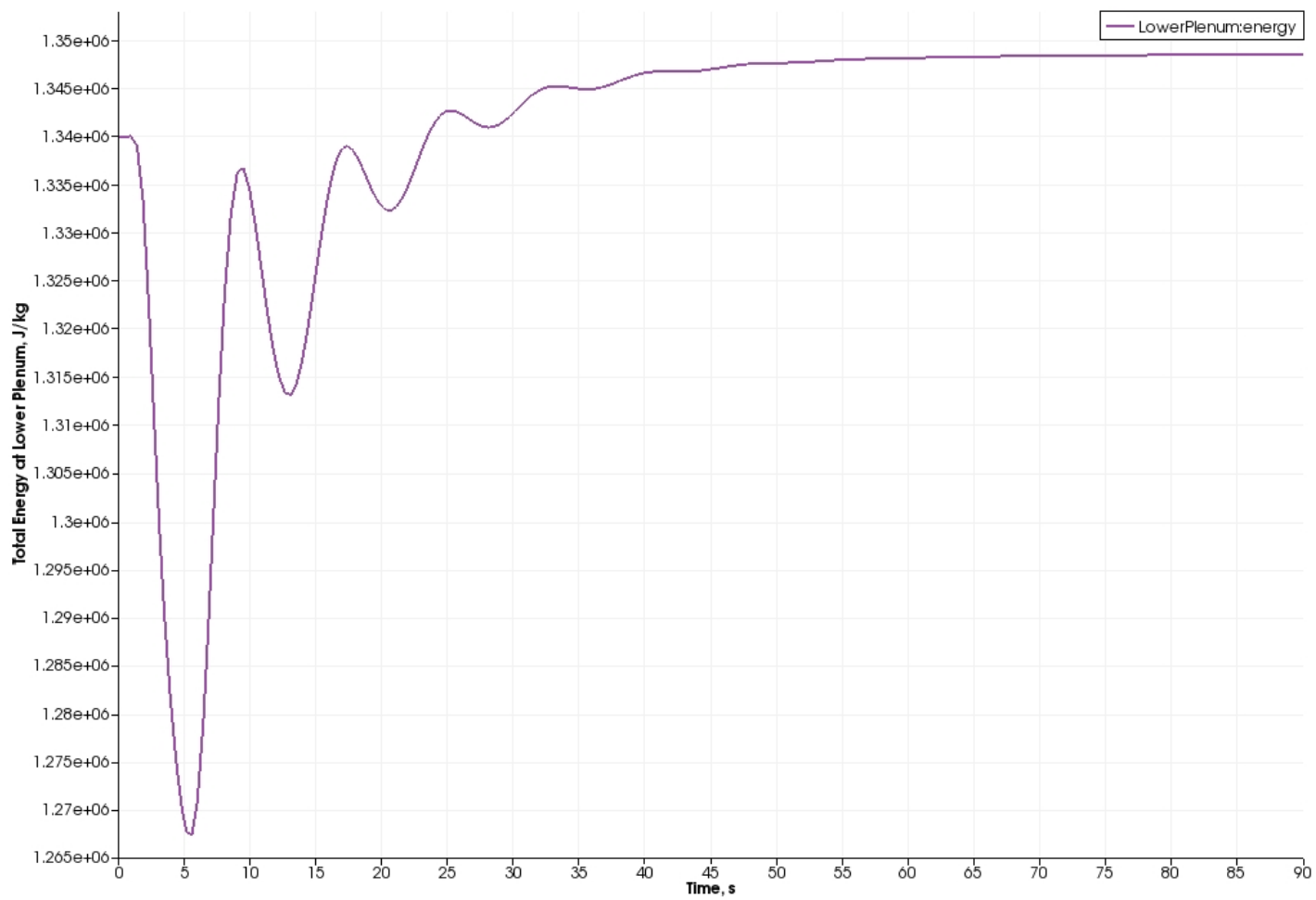

Figure 17. Calculated total specific energy in the lower plenum in the pressurizer for the PWR test. 


\section{SUMMARY}

As part of the efforts to expand the capability for PWR simulation, an equilibrium single-region pressurizer model has been implemented in RELAP-7. The pressurizer component can simulate pressure and water level change through insurge, spray, and heating processes. Two simple tests - one for insurge process and another for outsurge process have been reported to demonstrate and verify the functions of the pressurizer model. The typical single-phase PWR system model presented in the first RELAP-7 milestone report has been updated, as part of system level test for the new pressurizer model. The updated PWR system model with the pressurizer component can be used for more realistic transient simulations.

The addition of the equilibrium single-region pressurizer model represents the first step of developing a suite of pressurizer models with different levels of fidelity. Non-equilibrium two-region two-zone model and non-equilibrium five-region three zone model will be implemented in the near future. Cross comparison and validation will be pursued when higher fidelity pressurizer models are completed. 


\section{REFERENCES}

1. D. Andrs, et. al., RELAP-7 Level 2 Milestone Report: Demonstration of a Steady State Single Phase PWR Simulation with RELAP-7, INL/EXT-12-25924, May, 2012.

2. R.A. Berry, et. al., RELAP-7 Theory Manual, INL/EXT-14-31366, Feb, 2014.

3. H. Zhao, et. al., Refined Boiling Water Reactor Station Blackout Simulation with RELAP-7, INL/EXT-14-33162, September, 2014.

4. H. Zhang, et. al., RELAP-7 User's Guide, INL/EXT-14-33977, December, 2014.

5. H. Zhang, et. al., RELAP-7 Development Updates, INL/EXT-15-36763, September, 2015.

6. USNRC Technical Training Center, Reactor Concepts Manual - Pressurized Water Reactor (PWR) Systems.

7. N.E. Todreas and M.S. Kazimi, Nuclear System I, Thermal Hydraulic Fundamentals, Taylor \& Francis Group, 1990.

8. S.M. Baek, H.C. No, and I.Y. Park. "A nonequilibrium three-region model for transient analysis of pressurized water reactor pressurizer." Nuclear Technology, Vol. 74, no. 3, 260-266, 1986. 